Roudposhti, V.M., Nilashi, M., Mardani, A., Streimikiene, D., Samad, S., \&

Ibrahim, O. (2018). A new model for customer purchase intention in e-

commerce recommendation agents. Journal of International Studies, 11(4), 237-253.

doi:10.14254/2071-8330.2018/11-4/17

\title{
A new model for customer purchase intention in e-commerce recommendation agents
}

\author{
Vahid Mohseni Roudposhti \\ Faculty of Computing, Universiti Teknologi Malaysia (UTM), \\ Malaysia \\ vahid.mohseni1987@gmail.com
}

Mehrbakhsh Nilashi

Faculty of Computing, Universiti Teknologi Malaysia (UTM),

Malaysia

nilashidotnet@hotmail.com

\author{
Abbas Mardani \\ Azman Hashim International Business School, \\ Universiti Teknologi Malaysia (UTM), \\ Malaysia
}

Dalia Streimikiene

Lithuanian Institute of Agrarian Economics,

Vilnius, Lithuania

\section{Sarminah Samad}

$C B A$ Research Centre, Department of Business Administration,

Collage of Business and Administration, Princess Nourab Bint

Abdulrabman University, Saudi Arabia

sarminabsamad@hotmail.com

\section{Othman Ibrahim}

Faculty of Computing, Universiti Teknologi Malaysia (UTM),

Malaysia

Abstract. Recommender systems were introduced to improve the online shopping

Received:

April, 2018 experience by recommending appropriate products and services to customers according to their preferences. This research develops a new model by identifying the factors that influence customers' purchase intention in recommender systems. The research model of this study was developed by reviewing the previous studies on web-based information systems, e-commerce and recommender systems. Quantitative data was collected from questionnaires 
conducted among the customers of online shopping websites. The questionnaires was adopted from the previous researches, and validated by the experts in the fields of information systems and recommender systems. Descriptive and hypotheses' analyses were performed on the collected data using statistical analysis software and Partial Least Squares Structural Equation Modeling. The results reveal that Accuracy, Diversity, Ease of Use, Recommendation Quality, Satisfaction, Trust and Usefulness have significant influence on customers' intention to purchase a product recommended by the recommender systems. The developed model and the findings of this research will help e-commerce websites' developers and e-commerce providers to enhance the recommender systems based on the factors that contribute to their quality.

Keywords: e-commerce, recommender systems, trust, satisfaction, purchase intention.

JEL Classification: E31, F31, Q4, Z32

\section{INTRODUCTION}

Recommender systems are defined as techniques and software tools which offer products in online shopping websites to users according to their preferences (Pursel et al., 2016). They offer recommendations on different procedures of decision-making. As a decision-making system, recommender systems have been used by numerous online commerce websites, such as Amazon.com (Lu et al., 2015). They have brought benefits both to service providers and users. These systems help users in finding suitable items, thus lowering transaction costs. They have demonstrated the ability to improve the decision quality in online shopping environment (Pathak et al., 2010). For e-commerce players, the evidence shows that recommender systems can increase the sale of products (Schafer et al., 2001). The effect of recommender systems on product customization in e-commerce have been widely examined in the IS literature ( $\mathrm{Pu}$ et al., 2011; Nilashi et al., 2016; Komiak \& Benbasat, 2006). Personalized recommendations, in the most comprehensible form, can be considered as a set of items that are arranged according to their ranks to be recommended to users. In order to rank the items, the most appropriated products must be predicted by recommender systems. Accordingly, they should be accurate enough to meet the customers' satisfaction in online shopping websites. A survey in Germany showed that $65 \%$ of the German Internet users have bought items on the online commerce websites at more than 20 occasions. Additionally, already $10 \%$ of these online customers purchase items in the e-commerce website every day (Baier \& Stüber, 2010). This survey showed the significance of online shopping among German Internet users and the role of recommendation systems in their purchase decision-making.

Reichheld and Schefter (2000), Abrham et al. (2015), Zelazny (2017) or Ehrenberger et al. (2015) observe that there is a significant relationship between long-term growth, firm's profitability and customer purchase intention. The profit can intensely grow by slight rise in the percentage of customer retention. According to the "Choice Stream survey" as of 2007, 45\% of customers purchased from e-commerce websites that used recommendation system technology. In addition, nowadays customers would like to use the recommender system technology in their purchase decision-making (Pu et al., 2011). It means that determining and measuring the quality of customers' experience and customers' subjective attitudes towards the acceptance of recommendation system technology are important issues which were 
investigated by researchers in the field of web technologies (Komiak, \& Benbasat, 2006). If the recommender technology becomes accepted by users, it can highly increase customer likelihood to purchase the recommended to them items (Pursel et al., 2016). Recommender systems technology can motivate customers buy the products which have been suggested to them. Their total satisfaction will increase the probability of their return to the site and recommend this site to their friends (Pu et al., 2011), therefore, repeated purchase can occur. The main contribution of this research is in the development of an evaluation model which measures the perceived qualities of recommendations and users' behavioral intentions. This research provides a model to understand users' motivation in accepting recommendations. To do so, this research investigates the potential factors in improving of purchase intention from the customers' perspective. To date, few attempts have been made on this issue. The other significance of this study is its emphasis on the impact of recommendation quality on customer satisfaction. In addition, we investigate customers' satisfaction by recommender systems by the quality of recommended items based on novelty, diversity and accuracy of recommendations. The other contribution of this work embraces the importance of familiarity and trust in the domain of recommendation agents. To date, we can find few studies which have focused on the importance of users' familiarity and trust in the recommendation agents for $\mathrm{B} 2 \mathrm{C}$ websites.

The rest of this paper is organized as follows. In Section 2 the research problem statements are provided. In Section 3, TAM model is introduced. In Section 4, the conceptual framework and hypotheses are presented. In Section 5, data collection and analysis are provided. Finally, conclusion and discussion are presented in Section 6.

\section{PROBLEM STATEMENTS}

Recommender systems help users in their decision-making. Many studies have been conducted on improving the efficiency of these systems (Ricci et al., 2011; Nilashi et al., 2014; Bagherifard et al., 2017). ost of these previous studies focused on the accuracy of the recommendation algorithms (Bagherifard et al., 2017; Jannach et al., 2012), especially their prediction accuracy. Recommender systems and purchase intention in e-commerce have been two interesting topics among the researchers. The evidence by Google Trends shows that they are frequently searched by scholars (see Fig. 1). Despite the influence of recommender systems on user purchase intention, there is lack of a valuable set of factors to evaluate the level of this intention. That is going to be the primary goal of this research.

Although existing studies in literature have introduced a vast range of criteria for assessing the recommender systems, there are only a few studies evaluating the recommendation systems from the standpoint of customers' satisfaction and purchase intention. In addition, there have been only a few studies that have analysed the relationship between trust and satisfaction with their influence on customers' intention in what concerns recommender systems. Previous studies have been mostly conducted in the context of online retailing and commercial websites, and only a few studies were solely focused on recommender systems.

Furthermore, there is a need for other metrics that are less concentrated on technical issues in measuring wellbeing and usefulness of recommender systems. Since actual users of such systems have the credit to identify its success rather than its technical quality (Nilashi et al., 2016), user-centric factors should be evaluated to measure the quality and success of a recommender system. Accordingly, the aim of this study is to answer to this demand.

In this study Technology Acceptance Model is used to explore what are the acceptance and intention issues of users dealing with recommender systems. In other word, TAM is utilized in this study for measuring the customers' acceptance of recommendations to buy. Therefore, motivation for this study is 
that there has been little research assessing the effect of customers' objective opinions and satisfaction in the presence of recommender system's usage. This leads us to the following research questions:

What are the factors influencing customer purchase intention in e-commerce recommender systems?

What are the relationships among the factors behind customer purchase intention in e-commerce recommender systems?

What is the suitable model of customer purchase intention in e-commerce recommender systems?

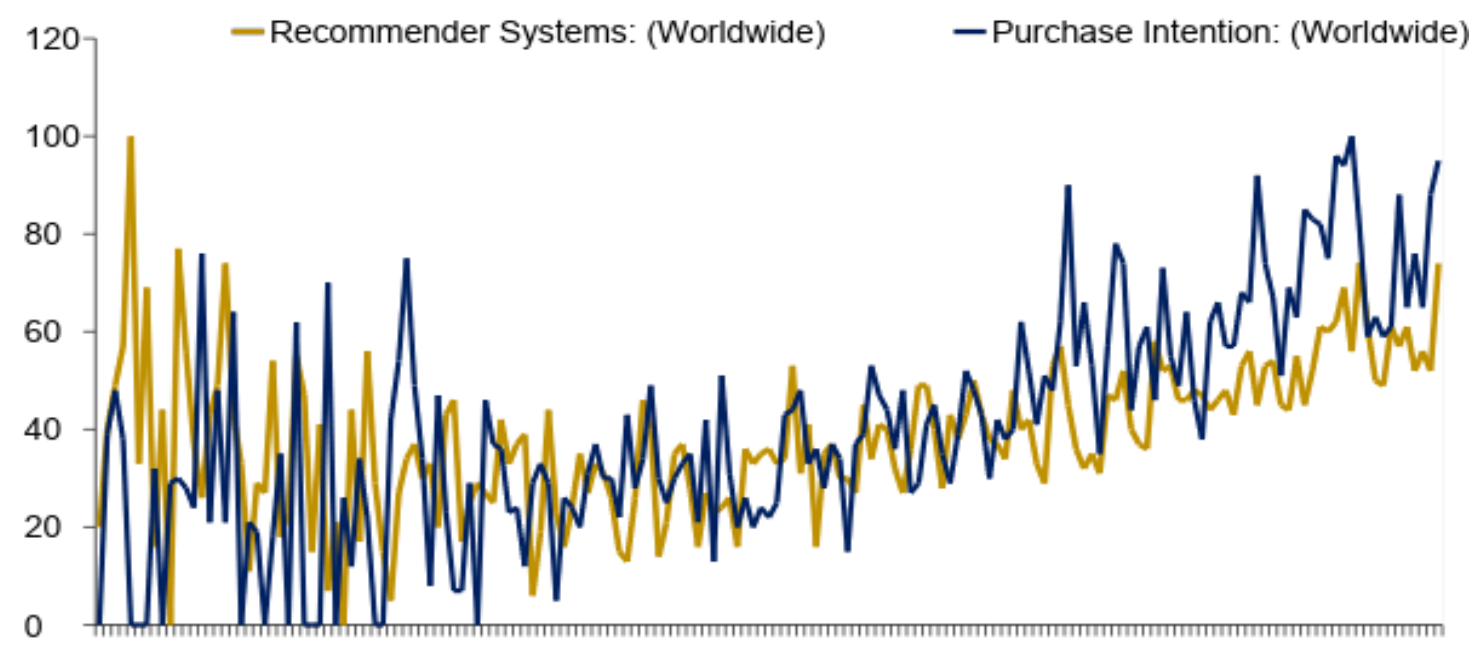

Figure 1. Importance of purchase intention and recommender systems in Google Trend

\section{TECHNOLOGY ACCEPTANCE MODEL (TAM)}

TAM (Technology Acceptance Model) is a theoretical model introduced by Davis (1989) to forecast the acceptance attitude of the individuals towards the information technology and whether such acceptance occurs under the effect of behavioral intention. The theory further maintains that the individuals' approach and standard toward such behavior are replaced by his/her 'Perceived Ease of Use' (PEU) and 'Perceived Usefulness' (PU). Many studies have investigated the TAM theory, and it is viewed as a strong model in technology acceptance studies. Fig. 2 illustrates the basic concepts of TAM. The proposed model of this study is based on TAM.

\section{CONCEPTUAL FRAMEWORK AND HYPOTHESIS}

In this study, TAM was used to evaluate some specific factors influencing the customer purchase intention in e-commerce recommender systems. This study have found some external variables and some factors which have logical relationship with TAM components and purchase intention, like: perceived novelty, perceived diversity, perceived accuracy, recommendation quality, satisfaction, customer trust, role of familiarity, perceived usefulness, perceived ease of use. The conceptual model is demonstrated in Fig. 3 and definition of each factor is presented in the next sections. According to Fig. 3, the following hypotheses are proposed.

H1: Perceived novelty (produces a direct positive effect on the quality of recommendation in the ecommerce recommender systems domain.

H2: Perceived diversity directly produces a positive effect on recommendation quality in the ecommerce recommendation systems domain.

H3: Perceived accuracy produces a direct positive effect on the quality of recommendation in the e- 
commerce recommender systems domain.

H4: Perceived recommendation quality directly produces a positive effect on the customers' satisfaction in the e-commerce recommender systems domain.

H5: Perceived usefulness produces a direct positive effect on the satisfaction of customers in the ecommerce recommender systems domain.

H6: Perceived ease of use directly produces positive effect on satisfaction of customers in the ecommerce recommender systems domain.

H7: Perceived satisfaction directly has positive effect on customers' purchase intention in the ecommerce recommender systems domain.

H8: Perceived familiarity produces direct positive effect on customer's trust in the e-commerce recommender systems domain.

H9: Perceived trust directly produces positive effect on the customer purchase intention in the ecommerce recommender systems domain.

Novelty. Pu et al., (2009) gave a definition on novelty. The 'novelty' concept denotes the recommendation system ability to teach the users and to assist them to find new suitable items. A distinction was then made between 'novelty' and 'serendipity' by Pursel et al. (2016) under the argument that 'novelty' only covered the concept of "new" whereas the serendipity comprised not only the "new" concept, but also "something wonderful". Nilashi et al. (2016) found that novelty has no positive impact on recommendation quality in recommender systems.

Diversity. The word 'diversity' commonly is defined in the literature as the average pairwise dissimilarity between recommended product items. The above notion was used by Zhang et al. (2011). Adomavicius \& Kwon (2012) posited that the 'diversity' is the system capability to place as many diverse items as possible in front of all population. In addition, 'diversity' identifies the level of difference in the recommended list. For a prepared list of recommendations, using an item based accuracy evaluation metric is not suitable for evaluation purposes. Studies have demonstrated that a low diversity at can cause low satisfaction, compelling them to leave the recommendation system (Sun et al., 2016). According to Zhang et al. (2011), diversity of items plays an important role in user acceptance of recommender systems.

Perceived Accuracy. The degree by which the users perceive that a recommendation is suitable to his/her preferences is called that 'perceived accuracy'. Generally it determines how efficiently the recommendation system can compute the users' preferences and desires (Pu et al., 2011). Accuracy is considered a major evaluation criterion in recommender systems (Pursel et al., 2016).

Recommendation Quality. As a measure, the recommendation quality evaluates the interest shown by the customer to the recommended products. This research evaluates three variables, perceived diversity, perceived novelty, and perceived accuracy, which have significant effect on recommendation quality.

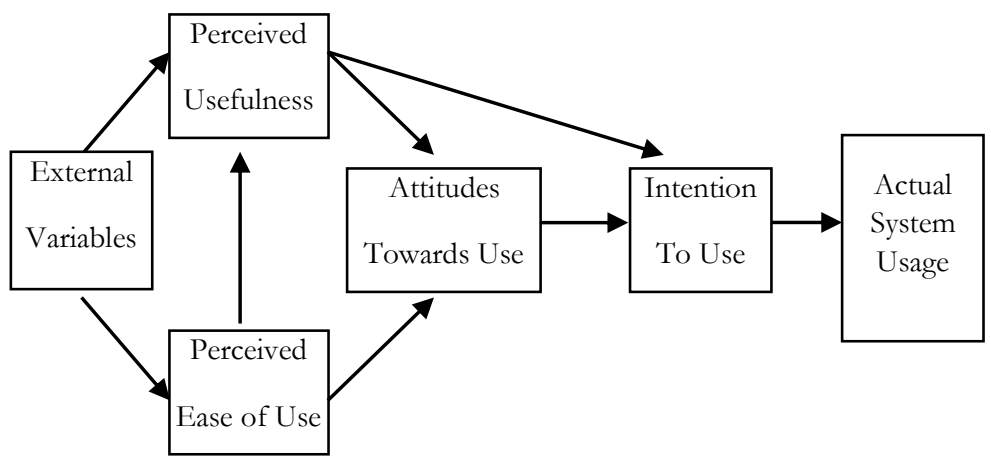

Figure 2. Basic Concept of TAM 


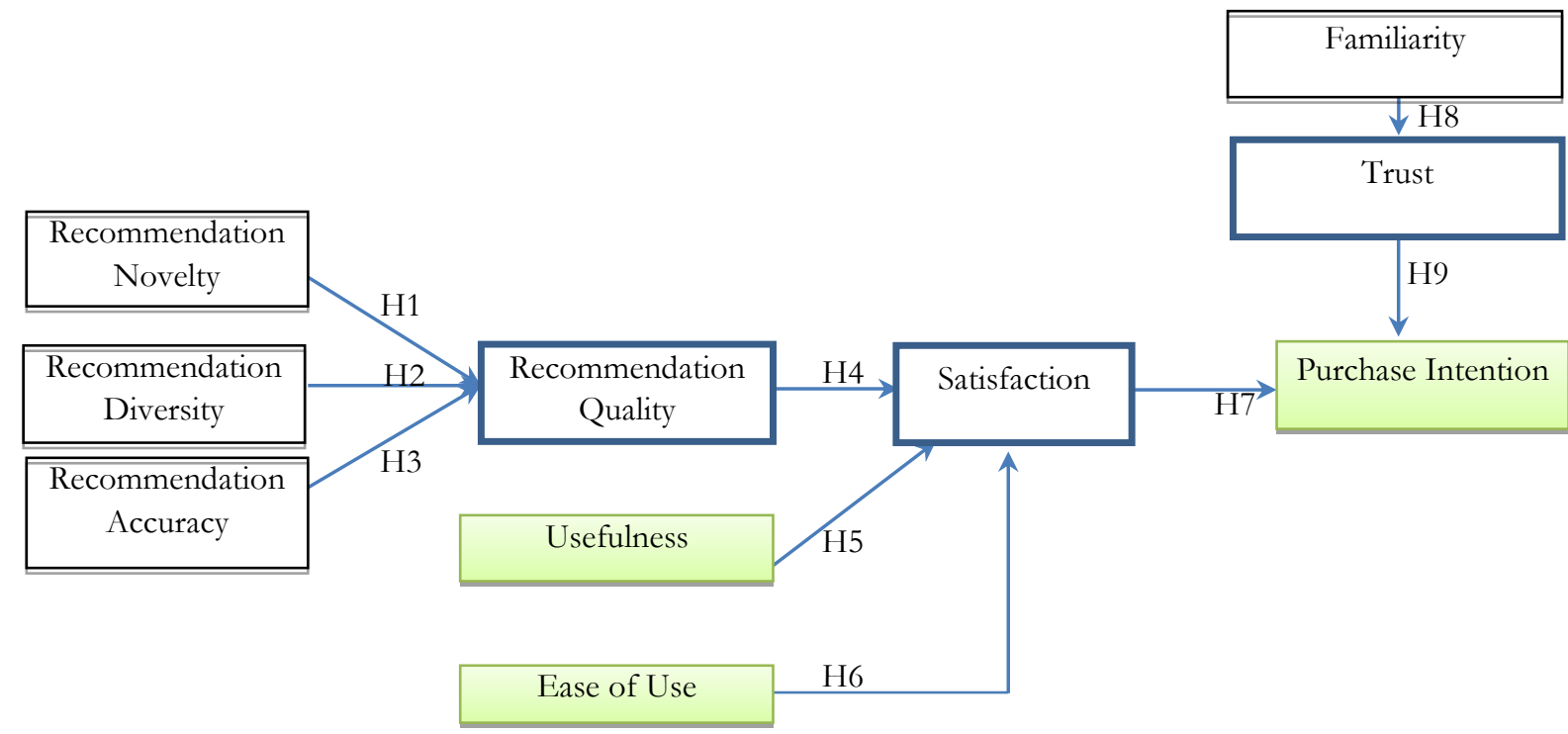

Figure 3. Research Model

Satisfaction. Customers' satisfaction has been widely studied in the literature in e-commerce (Ku \& Tai, 2013). Research concerning the association between satisfaction and customer behavior has revealed a relationship been satisfaction and customer purchase intention (Nilashi et al., 2016; Bilan, 2013; Abdoli et al, 2017; Ilie et al, 2017). It is assumed that the general satisfaction of customers with a recommender system to be highly connected to the observed quality of its recommendations and explanations (Tintarev \& Masthoff, 2012). Recently, more user-oriented assessment metrics has gained ground, including user satisfaction (McNee et al., 2006; Tintarev \& Masthoff, 2010; Ricci et al., 2010). Tintarev and Masthoff (2012) define satisfaction as "raise the ease of use or enjoyment".

Customer Trust. Although e-commerce introduced the convenience of purchasing product and services online, alongside the advantage, there exists a relatively high level of risk and trust deficiency (Furnell, 2005) which is perceived by customers due to the inherent self-service and lack of face to face interaction with the system (Polatidis \& Georgiadis, 2014). As Pu et al., (2010) declare, previous studies in most part are practiced in the e-commerce background more than recommender systems context, and their focus is adjusted on the concept of trust as an interrelation factor between a buyer and an e-vendor. Few studies, however, have addressed the reliance in the perspective of recommender system, in particular, focused on the idea of relying on the system and its serviceability. Trust is a value inferring to the fact that how much trustworthy the whole system is according to its users ( $\mathrm{Pu} \& \mathrm{Chen}, 2010)$. It is pictured as a set of personal beliefs that an individual perceives regarding certain attributes (Sun et al., 2016). It is explained as a belief that during an interchange, the supplier or service provider will deliver the determined product or services, in a determined and specified procedure (Ku \& Tai, 2013). As defined by Chen and $\mathrm{Pu}$ (2010), trust is the desire of customers to be susceptible or admit the possibility of lost while they experience online shopping.

Familiarity. According to Sun et al. (2015), familiarity is defined as the apprehension about an entity, which usually lies on the basis of prior interactions, experience, and learning of "the what, who, how, and when of what is happening". Familiarity with a recommender system is acquired through one's prior and direct experiential exchange with the recommender system. Komiak and Benbast (2006) found that "familiarity will increase cognitive trust in an RS's competence". After completing several shopping tasks with a recommender system, a customer will be more familiar with it, and will acquire a cognitive map of 
the procedures involved in that recommender system. Such a cognitive map provides the customer with an additional tool to use the same recommender system more quickly, with greater ease, and with fewer errors. Therefore, with higher familiarity, it is likely the customer will think the same recommender system is more effective and efficient.

Usefulness. A user attains perceived effectiveness when he/she learns that one's performance would improve by the use of a recommender system, as opposed to when they had not experienced the advantage of a recommender (Pursel et al., 2016). The usefulness/uselessness of this system to the users requires their opinions. Common recommenders in e-commerce settings chiefly help users to find appropriate information to encourage their buying decision. Purchasing in an e-commerce environment exemplifies the process of choosing appropriate items. Overall, decision technologies intend to conquer the confined rationality limit of users in order to assist them in more convincing decision making through a trifling attempt (Zhang et al., 2011). Users particularly take advantage of recommender systems to handle a huge body of information and make superior decisions under both time and knowledge restrictions. Furthermore, a confidence criterion can be used to assess the quality of decisions mediated by the system. The criterion specifies the confidence level of a user to believe in a correct choice was made possible by the use of a recommender ( $\mathrm{Pu} \& \mathrm{Chen}, 2011)$.

Ease of Use. Ease of use is the degree to which a user feels that using a recommender system would be free of effort. It has been a key factor in the acceptance of new technologies. The user friendly feature denotes the conceived intellectual attempt of users, i.e. the extent of users' attempt as far as they can comprehend. The novel preference elicitation process in recommender systems based on personality was investigated by $\mathrm{Hu}$ and $\mathrm{Pu}$ (2009), who evaluated the apprehended attempt consumed in the sign up stage. To compare with the perceived effort, they further recorded the real completion time (i.e., the objective effort). The ability of users to rapidly and properly complete tasks with convenience and no disappointment was studied by $\mathrm{Pu}$ et al. (2011), who intended to signify decision efficiency, that is, the magnitude of facilitation by a recommender system to help users swiftly obtain their desired items. Recommender systems in theory are expected to provide a good recommendation to mitigate the users' attempt expenditure (Polatidis \& Georgiadis, 2014).

Purchase Intention. Repurchase intentions have long been used by investigators to assist purchasing behavior prediction in the future. In recommendation context, the willingness of a user to purchase a certain product recommended by the recommender system is known as purchase intention. It has been shown that when the consumers trust the online store, she/he will be more likely to purchase in that store (Gefen et al., 2003). Nilashi et al. (2016) also found that there is a relationship between customers' trust and purchase intention in e-commerce recommendation systems.

\section{DATA COLLECTION AND ANALYSIS}

The questionnaire used for the study consisted of three main sections. The related literature and survey instruments established by previous researchers and a small group interview offered the basis for creating the questionnaire for this study. To certify the practicability, clarity, reliability and comprehensiveness of the questionnaire, a pilot study of this questionnaire was conducted among online shopping customers in Malaysia. In addition to detect potential bias in the instructions or contents of the instrument, it is verified by the scholars in the e-commerce field, who specialized in the areas of statistics and quantitative research. Based on their advices, some of questionnaire items are restructured.

The survey questionnaire is accessible into numerous sections for simple analysis and implication, whereby the easy English language is used and explicit questions are asked. Moreover, a short, simple and useful cover letter is shaped to notify the participants of the purposes and significance of the research. It is 
authored sensibly using clear language to inspire participants to offer the honest and impartial information. The questionnaire is structured into two sections for easy reading. In Sections A and B, the demographic variables, the online shopping and recommendation systems websites experience and its use are evaluated by using a nominal scale. The third section of the questionnaire $(C)$ is about the factors that influence the customers purchase intention in the recommender systems. There are nine variables (perceived novelty, perceived diversity, perceived ease of use, perceived usefulness, perceived satisfaction, perceived recommendation quality, perceived customer trust, perceived familiarity) that is adapted from previous studies. There are questions to measure each factor used for these constructs. A Five-point Likert scale response format was used for this section.

In the developed questioner, 10 factors have been considered to support the propose hypothesis. For each factors several items have been investigated from the literature. Totally, 10 construct and 21 items were considered to confirm the model of research. In Table 1, all construct along with items are presented.

Table 1

Constructs and Items

\begin{tabular}{|c|c|c|}
\hline Construct & $\begin{array}{l}\text { Item } \\
\text { No. }\end{array}$ & Item \\
\hline \multirow{2}{*}{ Novelty } & NO1 & The recommendation agent helps me discover new products. \\
\hline & NO2 & The recommended items by the recommender system are novel and interesting. \\
\hline \multirow{2}{*}{ Diversity } & DI1 & The recommended items by the recommender system are diverse. \\
\hline & DI2 & The recommended items by the recommender system are similar to each other. \\
\hline \multirow[t]{2}{*}{ Accuracy } & AC1 & $\begin{array}{l}\text { The recommended items by the recommender system are tailored to my } \\
\text { preference than what I may receive from a friend. }\end{array}$ \\
\hline & AC2 & The recommended items by the recommender system to me matched my interests. \\
\hline \multirow{2}{*}{$\begin{array}{l}\text { Recommendation } \\
\text { Quality }\end{array}$} & RQ1 & The recommended items by the recommender system helpful. \\
\hline & RQ2 & $\begin{array}{l}\text { I feel that the recommended items by the recommender system helped me decide } \\
\text { what items to buy. }\end{array}$ \\
\hline \multirow{3}{*}{ Satisfaction } & SA1 & I enjoy shopping from this website with the aid of the recommender system. \\
\hline & SA2 & I could find the items I wanted from this shopping website. \\
\hline & SA3 & This website provided a good shopping experience. \\
\hline \multirow{3}{*}{ Trust } & TR1 & I can trust the recommender system because of its accurate recommendation. \\
\hline & TR2 & The recommender system improved my trust for shopping from this website. \\
\hline & TR3 & I feel that this recommender system is trustworthy. \\
\hline \multirow{2}{*}{ Usefulness } & US1 & The ideal products I could effectively find by the aid the recommender system. \\
\hline & US2 & I feel supported in selecting the items to buy with the help of the recommender. \\
\hline \multirow[t]{2}{*}{ Ease of Use } & EU1 & $\begin{array}{l}\text { I became familiar with the recommender system used in the shopping website very } \\
\text { quickly. }\end{array}$ \\
\hline & EU2 & I easily found the items recommended by recommender system. \\
\hline \multirow{3}{*}{ Purchase Intention } & PI1 & I would buy the items recommended, given the opportunity. \\
\hline & PI2 & I predict that I will use this web site for my future shopping. \\
\hline & PI3 & I will intend to use this recommender system for my future shopping. \\
\hline \multirow{2}{*}{ Familiarity } & FA1 & The recommender system just provided me the familiar products. \\
\hline & FA2 & I am not familiar with the products recommended by the recommender system. \\
\hline
\end{tabular}


The data collected from the users who had experience with online shopping by Lazada.com. Lazada.com is a popular online shopping platform among Malaysian customers (see Fig. 4). In recent years, the online shopping through this website has been increased. It provides a complete platform for customers to do the online shopping and business to sell the products. For main survey to validate the research model and test the research hypotheses, overall 231 respondents were considered. The researcher used SmartPLS and SPSS v.22 software to present the respondent's demographic background. In Table 2 the frequencies and percentages among the respondents in the survey are presented. The respondents have been selected at the Universiti Teknologi Malaysia (UTM). All of them had experience with the online shopping in e-commerce websites. In addition they were familiar with the recommender systems technology in online shopping websites. As shown in Table 2, 154 respondents $(66.67 \%)$ were male and 77 respondents (33.33\%) were female. Furthermore, 64 respondents $(27.71 \%)$ had experience less than 2 years in online shopping with the Lazada.com and also 116 respondents $(50.22 \%)$ had 2-5 years' experience and $22.08 \%$ had more than 5 years' experience in online shopping with the Lazada.com. Moreover, descriptive analysis also reveals that $61.90 \%$ of the respondents were Master student and $38.10 \%$ were $\mathrm{PhD}$ students.

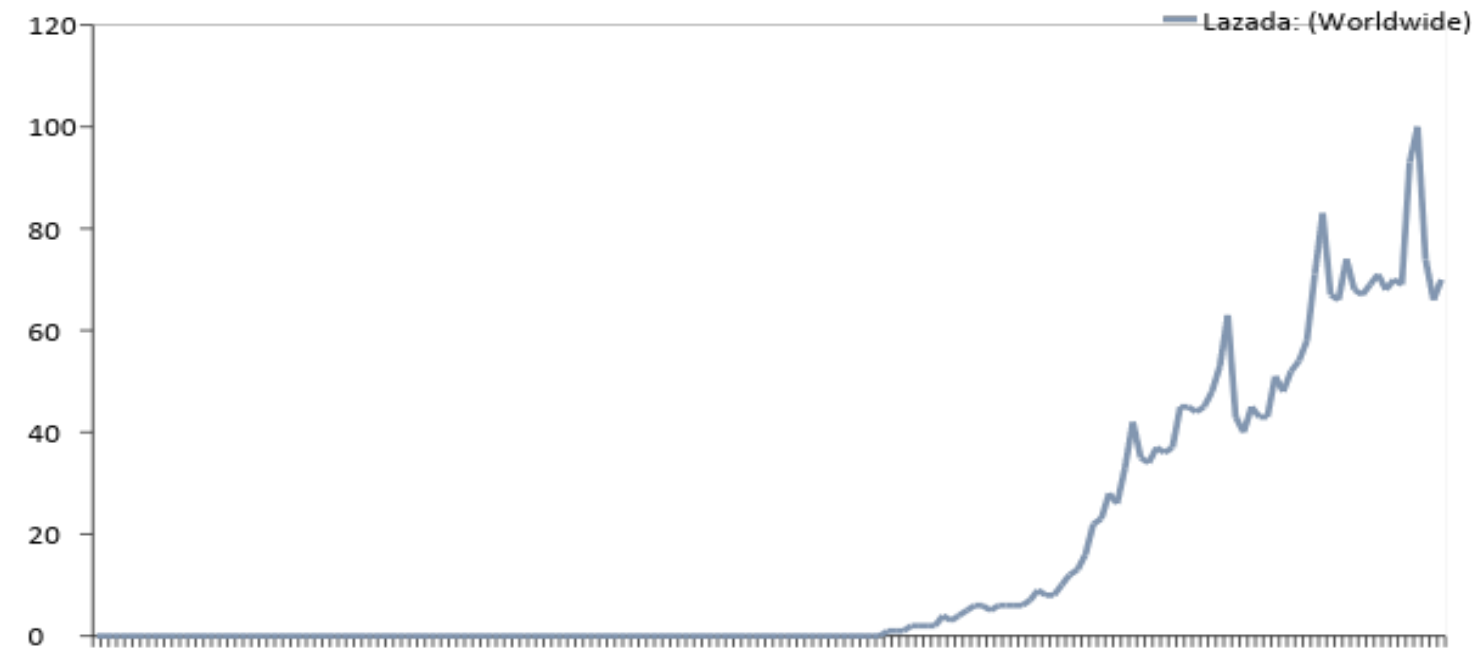

Figure 4. Importance of Lazada in Google Trend

Demographic information of respondents in main survey

\begin{tabular}{|l|c|c|c|}
\hline \multirow{4}{*}{ Age } & Items & Frequency & $\%$ \\
\cline { 2 - 4 } & 23 & 56 & 24.24 \\
\cline { 2 - 4 } & $24-28$ & 78 & 33.77 \\
\cline { 2 - 4 } & $29-31$ & 44 & 19.05 \\
\hline \multirow{4}{*}{ Gender } & $>31$ & 53 & 22.94 \\
\cline { 2 - 4 } & Male & 154 & 66.67 \\
\hline \multirow{2}{*}{ Education } & Female & 77 & 33.33 \\
\hline \multirow{2}{*}{ Experience with Lazada.com } & Master stud. & 143 & 61.90 \\
\cline { 2 - 4 } & Ph.D. stud. & 88 & 38.10 \\
\cline { 2 - 4 } & $<2$ Years & 64 & 27.71 \\
\cline { 2 - 4 } & $2-5$ Years & 116 & 50.22 \\
\cline { 2 - 4 } & $>5$ Years & 51 & 22.08 \\
\hline
\end{tabular}


The first analysis was indicator reliability and internal consistency reliability for measurement model assessment. The values of outer loadings exhibited in Table 3 shows that there is no issue for the indicator reliability of the measurement model.

The internal consistency reliability of constructs is assessed against two criteria of Cronbach's alpha and composite reliability. Referring to Table 4, all constructs met the acceptable values for criteria of Cronbach's alpha and composite reliability which should be more than 0.7 .

In this research we evaluated the discriminant validity of survey (Hair et al., 2016). Through examining the cross-loadings matrix and Fornell-Larcker criterion, the discriminant validity was verified (Hair et al., 2016). In cross loadings matrix, the aim is to find the item loading of each indicator which should be greater than all of the other constructs loadings. In Fornell-Larcker, the square root of the AVE for each construct was considered.

Table 3

Indicator Reliability Assessment

\begin{tabular}{|c|c|c|}
\hline Construct & Measurement item & Outer loading \\
\hline \multirow[t]{2}{*}{ Accuracy } & AC01 & 0.842 \\
\hline & $\mathrm{ACO} 2$ & 0.971 \\
\hline \multirow[t]{2}{*}{ Diversity } & $\mathrm{DI01}$ & 0.964 \\
\hline & $\mathrm{DI} 02$ & 0.962 \\
\hline \multirow[t]{2}{*}{ Ease of use } & EU02 & 0.893 \\
\hline & EU03 & 0.914 \\
\hline \multirow[t]{2}{*}{ Familiarity } & FA01 & 0.950 \\
\hline & FA02 & 0.880 \\
\hline \multirow[t]{2}{*}{ Novelty } & NO01 & 0.778 \\
\hline & NO03 & 0.993 \\
\hline \multirow[t]{3}{*}{ Purchase intention } & PI01 & 0.861 \\
\hline & PI02 & 0.822 \\
\hline & PI03 & 0.863 \\
\hline \multirow[t]{2}{*}{ Recommendation quality } & RQ01 & 0.958 \\
\hline & RQ02 & 0.952 \\
\hline \multirow[t]{3}{*}{ Satisfaction } & SA01 & 0.889 \\
\hline & SA02 & 0.813 \\
\hline & SA04 & 0.897 \\
\hline \multirow[t]{3}{*}{ Trust } & TR01 & 0.845 \\
\hline & TR02 & 0.878 \\
\hline & TR04 & 0.857 \\
\hline \multirow[t]{2}{*}{ Usefulness } & US01 & 0.949 \\
\hline & US02 & 0.909 \\
\hline
\end{tabular}


Internal Consistency Reliability

\begin{tabular}{|l|c|c|}
\hline \multicolumn{1}{|c|}{ Construct } & Composite Reliability & Cronbach's alpha \\
\hline Accuracy & 0.904 & 0.815 \\
\hline Diversity & 0.962 & 0.921 \\
\hline Ease of use & 0.898 & 0.774 \\
\hline Familiarity & 0.912 & 0.815 \\
\hline Novelty & 0.885 & 0.824 \\
\hline Purchase intention & 0.886 & 0.806 \\
\hline Recommendation quality & 0.954 & 0.904 \\
\hline Satisfaction & 0.901 & 0.834 \\
\hline Trust & 0.895 & 0.824 \\
\hline Usefulness & 0.927 & 0.845 \\
\hline
\end{tabular}

The values of AVE are all well above the threshold of 0.50 and indicate that the measurement model has no issues regarding its convergent validity. As exhibited in Table 5, the root square of each construct's AVE value is higher than any other construct which correlated to it. Hence, Fornell-Larcker criterion provides evidence for the constructs' discriminant validity.

In Table 6, the results of discriminant validity assessment are presented. As can be seen in Table 6, for each construct the square root of the AVE (diagonal elements) is greater than other values in the matrix. Therefore, the figure in below gives an evidence that all reflective constructs and sub-constructs in the research model of this study displayed adequate discriminant validity.

Consequently, taking the results of two methods altogether, there was strong evidence to support the discriminant validity of the constructs proposed in the model. Accordingly, based on the validity tests and construct reliability, the measurement models have been successfully validated in the pilot survey.

Table 5

Convergent Validity Assessment

\begin{tabular}{|l|l|}
\hline \multicolumn{1}{|c|}{ Construct } & AVE \\
\hline Accuracy & 0.826 \\
\hline Diversity & 0.927 \\
\hline Ease of use & 0.816 \\
\hline Familiarity & 0.838 \\
\hline Novelty & 0.796 \\
\hline Purchase intention & 0.721 \\
\hline Recommendation quality & 0.912 \\
\hline Satisfaction & 0.752 \\
\hline Trust & 0.740 \\
\hline Usefulness & 0.864 \\
\hline
\end{tabular}


Table 6

Discriminant Validity Assessment

\begin{tabular}{|c|c|c|c|c|c|c|c|c|c|c|}
\hline Construct & $\mathrm{AC}$ & DI & $\mathrm{EU}$ & FA & $\mathrm{NO}$ & PI & RQ & SA & TR & $\overline{\mathrm{US}}$ \\
\hline Accuracy & 0.909 & & & & & & & & & \\
\hline Diversity & -0.042 & 0.963 & & & & & & & & \\
\hline Ease of use & 0.093 & 0.097 & 0.903 & & & & & & & \\
\hline Familiarity & 0.136 & 0.009 & -0.034 & 0.916 & & & & & & \\
\hline Novelty & 0.134 & 0.068 & 0.085 & 0.092 & 0.892 & & & & & \\
\hline Purchase intention & 0.091 & 0.054 & 0.081 & 0.192 & -0.110 & 0.849 & & & & \\
\hline Recommendation quality & 0.181 & 0.300 & 0.201 & 0.163 & 0.059 & 0.252 & 0.955 & & & \\
\hline Satisfaction & 0.144 & 0.116 & 0.219 & 0.108 & 0.023 & 0.476 & 0.405 & 0.867 & & \\
\hline Trust & 0.037 & 0.160 & -0.099 & 0.121 & -0.128 & 0.609 & 0.118 & 0.307 & 0.860 & \\
\hline Usefulness & -0.038 & 0.123 & 0.084 & 0.107 & 0.098 & 0.175 & 0.212 & 0.198 & 0.172 & 0.929 \\
\hline
\end{tabular}

To begin with, the structural model should be assessed against collinearity issues by examining the values of VIF and the level of tolerance. Statistical software package, IBM SPSS, was utilized to perform collinearity assessment. As presented in Table 7, the values of tolerance and VIF passed the thresholds (respectively more than 0.20 and less than 5). Hence, it can be concluded that the all the constructs included in the proposed model aiming to predict the intention were not correlated and consequently no construct is needed to be eliminated from the model.

Table 7

Collinearity Assessment for the Structural Model

\begin{tabular}{|l|c|l|l|l|l|l|l|l|l|l|l|}
\hline \multicolumn{3}{|c|}{ Fist set } & \multicolumn{3}{c|}{ Second set } & \multicolumn{3}{c|}{ Third set } & \multicolumn{3}{c|}{ Fourth set } \\
\hline & Tolerance & VIF & & Tolerance & VIF & & Tolerance & VIF & & Tolerance & VIF \\
\hline AC & 0.980 & 1.021 & RQ & 0.921 & 1.085 & FA & 1.000 & 1.000 & SA & 0.906 & 1.104 \\
\hline DI & 0.993 & 1.007 & EU & 0.958 & 1.044 & & & & TR & 0.906 & 1.104 \\
\hline NO & 0.977 & 1.024 & US & 0.953 & 1.049 & & & & & & \\
\hline
\end{tabular}

In Fig. 5 and Table 8 we present the significance testing results of the structural model path coefficients. The R2 values of purchase intention, trust, satisfaction, and recommendation quality which are the four dependent constructs of this study were $0.46,0.02,0.20$, and 0.13 , respectively, which all are considered as weak. As depicted in Fig. 5, all the path coefficients were significant with different p-values except the path coefficients of the relationships between familiarity and trust, and novelty and recommendation quality.

Hypothesis 1 states that novelty positively influences recommendation quality. From Fig. 5, it can be observed that while there is a positive relationship between these two factors but it is not significant regarding its $\mathrm{t}$-value $(\beta=0.012, \mathrm{t}=0.158, \mathrm{p}>0.10)$. The results revealed that novelty was not statistically related to recommendation quality, and hence, Hypothesis 1 was rejected.

Hypothesis 2 states that diversity positively influences recommendation quality. From Fig. 5, it can be observed that there is a significant impact of DI on RQ $(\beta=0.307, \mathrm{t}=4.812, \mathrm{p}<0.01)$. The results revealed that DI was statistically related to RQ, and hence, Hypothesis 2 was accepted. 
Hypothesis 3 states that accuracy positively influences recommendation quality. From Fig. 5, it can be observed that there is a significant impact of AC on RQ $(\beta=0.192, t=3.251, p<0.01)$. The results revealed that AC was statistically related to RQ, and hence, Hypothesis 3 was accepted.

Hypothesis 4 states that recommendation quality positively influences satisfaction. From Fig. 5, it can be observed that there is a significant impact of RQ on SA $(\beta=0.354, t=5.014, p<0.01)$. The results revealed that RQ was statistically related to SA, and hence, Hypothesis 4 was accepted.

Hypothesis 5 states that usefulness positively influences satisfaction. From Fig. 5, it can be observed that there is a significant impact of US on SA $(\beta=0.111, \mathrm{t}=1.885, \mathrm{p}<0.10)$. The results revealed that US was statistically related to SA while it was significant at $90 \%$ level of confidence, and hence, Hypothesis 5 was accepted.

Hypothesis 6 states that ease of use positively influences satisfaction. From Fig. 5, it can be observed that there is a positive and significant impact of EU on SA $(\beta=0.139, \mathrm{t}=2.472, \mathrm{p}<0.05)$. The results revealed that EU was statistically related to SA while it was significant at $95 \%$ level of confidence, and hence, Hypothesis 6 was accepted.

Hypothesis 7 states that satisfaction positively influences purchase intention. From Fig. 5, it can be observed that there is a positive and significant impact of SA on PI $(\beta=0.319, \mathrm{t}=5.153, \mathrm{p}<0.01)$. The results revealed that SA was statistically related to PI, and hence, Hypothesis 7 was accepted.

Hypothesis 8 states that familiarity positively influences trust. From Fig. 5, it can be observed that while there is a positive relationship between these two factors but it is not significant regarding its $\mathrm{t}$-value $(\beta=0.121, \mathrm{t}=1.532, \mathrm{p}>0.10)$. The results revealed that FA was not statistically related to trust, and hence, Hypothesis 8 was rejected.

Hypothesis 9 states that trust positively influences purchase intention. From Fig. 5, it can be observed that there is a positive and significant impact of TR on PI $(\beta=0.511, \mathrm{t}=9.238, \mathrm{p}<0.01)$. The results revealed that TR was significantly related to PI, and hence, Hypothesis 9 was accepted. 


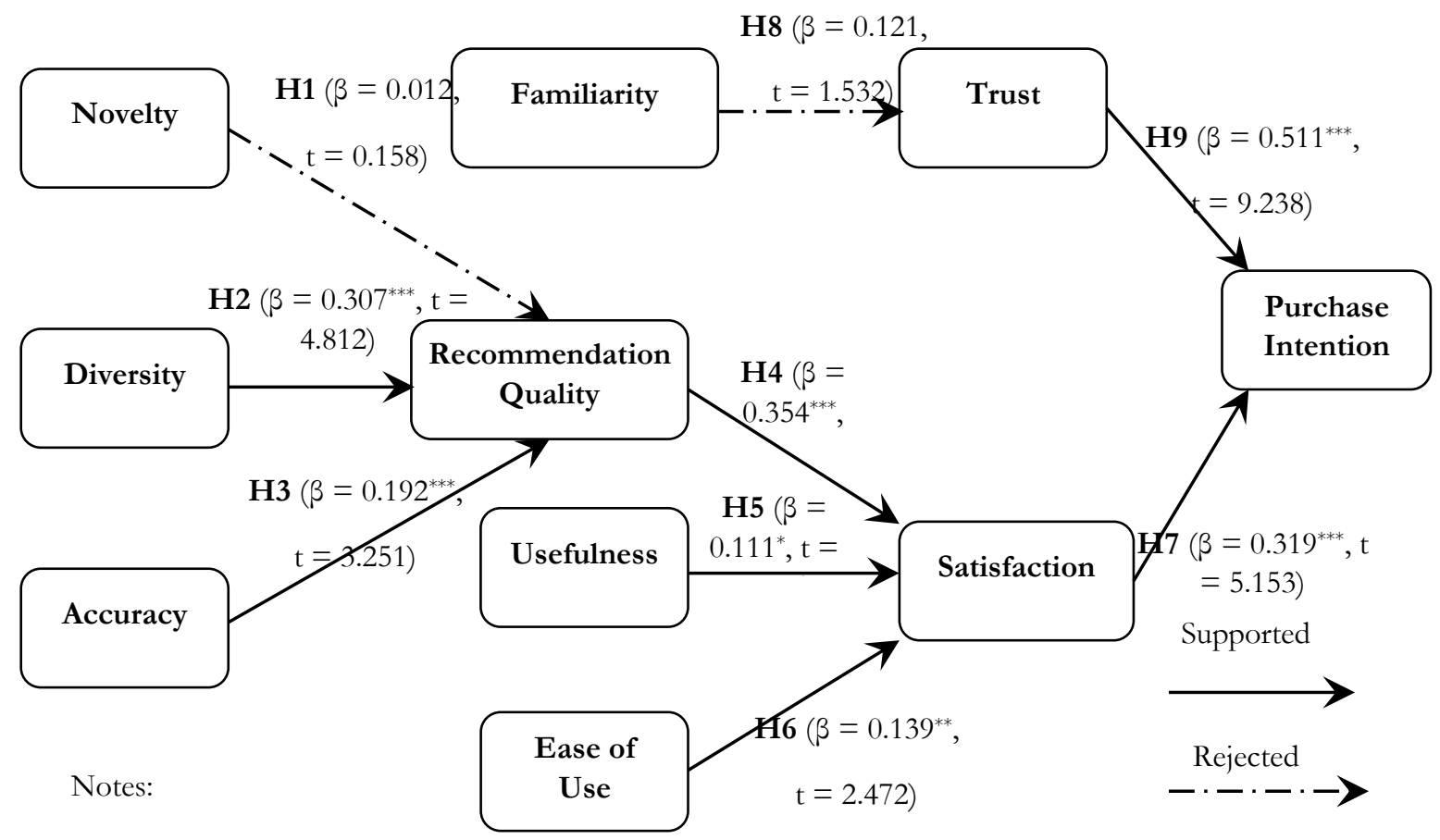

$*$ Significance level $=0.10$ (two-

tailed test) $* *$ Significance

level $=0.050$ (two-tailed test)

$* * *$ Significance level $=0.01$ (two-

tailed test)

Figure 5. Results of the Structural Model

Table 8

Summary of the Structural Model

\begin{tabular}{|l|l|l|l|l|l|l|}
\hline \multicolumn{1}{|c|}{ Hypothesis } & \multicolumn{1}{|c|}{ Description } & Path Coefficient & t-Value & p-Value & Significance Level & \multicolumn{1}{c|}{ Results } \\
\hline H1 & NV $\rightarrow$ RQ & 0.012 & 0.158 & 0.875 & NS & Not Supported \\
\hline H2 & DI $\rightarrow$ RQ & 0.307 & 4.812 & 0.000 & $* * *$ & Supported \\
\hline H3 & AC $\rightarrow$ RQ & 0.192 & 3.251 & 0.001 & $* * *$ & Supported \\
\hline H4 & RQ $\rightarrow$ SA & 0.354 & 5.014 & 0.000 & $* * *$ & Supported \\
\hline H5 & US $\rightarrow$ SA & 0.111 & 1.885 & 0.061 & $*$ & Supported \\
\hline H6 & EU $\rightarrow$ SA & 0.139 & 2.472 & 0.014 & $* *$ & Supported \\
\hline H7 & SA $\rightarrow$ PI & 0.319 & 5.153 & 0.000 & $* * *$ & Supported \\
\hline H8 & FA $\rightarrow$ TR & 0.121 & 1.532 & 0.127 & NS & Not Supported \\
\hline H9 & TR $\rightarrow$ PI & 0.511 & 9.238 & 0.000 & $* * *$ & Supported \\
\hline
\end{tabular}

Notes: NS $=$ not significant. ${ }^{*}$ Significance level $=\% 10$ (2-tailed test); ${ }^{* *}$ Significance level $=\% 5$ (2-tailed test); ${ }^{* *}$ Significance level $=\% 1$ (2-tailed test).

\section{DISCUSSION AND CONCLUSION}

The objectives of this research are concerned with the establishment of satisfaction and trust for improving the customer's intention to purchase the items recommended by the recommender systems and examination of a research framework as well as testing research hypotheses to assess the significant 
determinants of satisfaction and trust on intention to purchase. The following section summarizes the achievements of this study based on the research objectives.

To recall, the first objective of this study was to find the factors influencing the customer purchase intention in e-commerce recommender systems. In line of this, the researcher reviewed mainly the existing literature on the recommender systems and IS theories. The review also included a critical analysis of relevant theories and suggested the most imperative or potential factors for increasing the customer's trust and satisfaction in recommender systems. In details, the TAM theory was suggested as the most appropriate theory for developing a theoretical framework for customer intention to purchase in recommender systems. In addition to that, Accuracy, Diversity, Ease of use, Familiarity, Recommendation quality, Satisfaction, Trust and Usefulness were found to have significant influence on customer's intention to purchase an item recommended by the recommender systems.

The second and third research objectives were determining the relationships among the factors for customer's purchase intention in e-commerce recommender systems, and accordingly developing and validating a theoretical framework which has been accomplished by the quantitative study analysis. The quantitative analysis-phase involved the development of the questionnaire for the research survey, collecting respondents' data, and analyzing the data using PLS method. In details, the process of developing an instrument for data collection was discussed and pilot survey was conducted to acquire an overview of data applicability in this research. In addition to that, PLS method has been used to validate the measurement model.

An online survey was conducted to the students at Universiti Teknologi Malaysia (UTM), who had experience with the online shopping, to test the research hypotheses. The results of the quantitative analysis were presented precisely. These results indicate that the research framework provides an effective prediction of the customer's intention to buy the recommendations. In addition, the hypotheses testing results show that out of 9 hypotheses, 7 hypotheses were accepted.

\section{REFERENCES}

Abdoli, M., Rostamzadeh, R., Feizi, J., \& Joksiene, I. (2017). Impact of Perceived Value and Satisfaction on Customer Loyalty in Banking Industry. Transformations in Business \& Economics, 16(2A) (41A), 421-441.

Abrham, J., Strielkowski, W., Vošta, M., \& Šlajs, J. (2015) Factors that influence the competitiveness of Czech rural small and medium enterprises. Agricultural Economics-Zemedelska Ekonomika, 61(10), 450-460. doi:10.17221/63/2015-AGRICECON

Adomavicius, G., \& Kwon, Y. (2012). Improving aggregate recommendation diversity using ranking-based techniques. Knowledge and Data Engineering, IEEE Transactions on, 24(5), 896-911.

Al-Taie, M. Z. (2013). Explanations in recommender systems: overview and research approaches. In Proceedings of the 14th International Arab Conference on Information Technology, Khartoum, Sudan, ACIT (Vol. 13).

Bagherifard, K., Rahmani, M., Nilashi, M., \& Rafe, V. (2017). Performance improvement for recommender systems using ontology. Telematics and Informatics, 34(8), 1772-1792.

Baier, D., \& Stüber, E. (2010). Acceptance of recommendations to buy in online retailing. Journal of Retailing and Consumer Services, 17(3), 173-180.

Bilan, Y. (2013). Sustainable development of a company: Building of new level relationship with the consumers of XXI century. Amfiteatru Economic Journal, 15(Special No. 7), 687-701.

Chen, L., \& Pu, P. (2010). Experiments on the preference-based organization interface in recommender systems. ACM Transactions on Computer-Human Interaction (TOCHI), 17(1), 5.

Davis, F. D. (1989). Perceived usefulness, perceived ease of use, and user acceptance of information technology. MIS quarterly, 319-340. 
Ehrenberger, M., Koudelkova, P., \& Strielkowski, W. (2015). Factors influencing innovation in small and medium enterprises in the Czech Republic. Periodica Polytechnica Social and Management Sciences, 23(2), 73-83. https://doi.org/10.3311/PPso.7737

Felfernig, A., \& Gula, B. (2006). An empirical study on consumer behavior in the interaction with knowledge-based recommender applications (p. 37). IEEE.

Furnell, S. M. (2005, December). Considering the security challenges in consumer-oriented eCommerce. In Signal Processing and Information Technology, 2005. Proceedings of the Fifth IEEE International Symposium on (pp. 534-539). IEEE.

Gefen, D., Karahanna, E., \& Straub, D. W. (2003). Trust and TAM in online shopping: An integrated model. MIS quarterly, 27(1), 51-90.

Hair Jr, J. F., Hult, G. T. M., Ringle, C., \& Sarstedt, M. (2016). A primer on partial least squares structural equation modeling (PLS-SEM). Sage Publications.

Hu, R., \& Pu, P. (2009, October). Acceptance issues of personality-based recommender systems. In Proceedings of the third ACM conference on Recommender systems (pp. 221-224). ACM.

Ilie, M., Moraru, Andreea-Daniela, Ghita-Mitrescu, Silvia. (2017). The Hierarchical Determination of Customer Satisfaction with Banking Services Using an Artificial Neural Network. Transformations in Business \& Economics, 16(2A) (41A), 401-421.

Jannach, D., Karakaya, Z., \& Gedikli, F. (2012, June). Accuracy improvements for multi-criteria recommender systems. In Proceedings of the 13th ACM conference on electronic commerce (pp. 674-689). ACM.

Komiak, S. Y., \& Benbasat, I. (2006). The effects of personalization and familiarity on trust and adoption of recommendation agents. MIS quarterly, 941-960.

Lu, J., Wu, D., Mao, M., Wang, W., \& Zhang, G. (2015). Recommender system application developments: a survey. Decision Support Systems, 74, 12-32.

McNee, S. M., Riedl, J., \& Konstan, J. A. (2006, April). Making recommendations better: an analytic model for human-recommender interaction. In CHI'06 extended abstracts on Human factors in computing systems (pp. 11031108). ACM.

Nilashi, M., bin Ibrahim, O., \& Ithnin, N. (2014). Hybrid recommendation approaches for multi-criteria collaborative filtering. Expert Systems with Applications, 41(8), 3879-3900.

Nilashi, M., Jannach, D., bin Ibrahim, O., Esfahani, M. D., \& Ahmadi, H. (2016). Recommendation quality, transparency, and website quality for trust-building in recommendation agents. Electronic Commerce Research and Applications, 19, 70-84.

Pathak, B., Garfinkel, R., Gopal, R. D., Venkatesan, R., \& Yin, F. (2010). Empirical analysis of the impact of recommender systems on sales. Journal of Management Information Systems, 27(2), 159-188.

Polatidis, N., \& Georgiadis, C. K. (2014, June). Factors influencing the quality of the user experience in ubiquitous recommender systems. In International Conference on Distributed, Ambient, and Pervasive Interactions (pp. 369-379). Springer, Cham.

Pu, P., Chen, L., \& Hu, R. (2011, October). A user-centric evaluation framework for recommender systems. In Proceedings of the fifth ACM conference on Recommender systems (pp. 157-164). ACM.

Pursel, B., Liang, C., Wang, S., Wu, Z., Williams, K., Brautigam, B., ... \& Giles, C. L. (2016, April). BBookX: Design of an Automated Web-based Recommender System for the Creation of Open Learning Content. In Proceedings of the 25th International Conference Companion on World Wide Web (pp. 929-933). International World Wide Web Conferences Steering Committee.

Reichheld, F. F., \& Schefter, P. (2000). E-loyalty: your secret weapon on the web. Harvard business review, 78(4), 105113.

Ricci, F., Rokach, L., \& Shapira, B. (2011). Introduction to recommender systems handbook (pp. 1-35). Springer US.

Schafer, J. B., Konstan, J., \& Riedl, J. (1999, November). Recommender systems in e-commerce. In Proceedings of the 1st ACM conference on Electronic commerce (pp. 158-166). ACM.

Sinha, R., \& Swearingen, K. (2002, April). The role of transparency in recommender systems. In CHI'02 extended abstracts on Human factors in computing systems (pp. 830-831). ACM. 
Sinha, R. R., \& Swearingen, K. (2001, June). Comparing recommendations made by online systems and friends. In DELOS workshop: personalisation and recommender systems in digital libraries (Vol. 106).

Sun, Y., Chong, W. K., Han, Y. S., Rho, S., \& Man, K. L. (2015, January). Key factors affecting user experience of mobile recommendation systems. In Proceedings of the International MultiConference of Engineers and Computer Scientists (Vol. 2).

Sun, Y., Chong, W. K., Man, K. L., Rho, S., \& Xie, D. (2016). Exploring critical success factors of mobile recommendation systems: The end user perspective. In Transactions on Engineering Technologies (pp. 45-57). Springer, Singapore.

Tintarev, N., \& Masthoff, J. (2012). Evaluating the effectiveness of explanations for recommender systems. User Modeling and User-Adapted Interaction, 22(4-5), 399-439.

Venkatesh, V., \& Davis, F. D. (2000). A theoretical extension of the technology acceptance model: Four longitudinal field studies. Management science, 46(2), 186-204.

Xiao, B., \& Benbasat, I. (2007). E-commerce product recommendation agents: use, characteristics, and impact. MIS quarterly, 31(1), 137-209.

Żelazny, R. (2017). Determinants and measurement of smart growth: evidence from Poland. Journal of International Studies, 10(1), 34-45.

Tongxiao (Catherine) Zhang, Agarwal, R., \& Lucas Jr, H. C. (2011). The value of IT-enabled retailer learning: personalized product recommendations and customer store loyalty in electronic markets. Mis Quarterly, 859881. 